Peer-reviewed research

\title{
Can Uncertainty Due to Pandemic Predict Asia-Pacific Energy Stock Markets?
}

\author{
Ismail O. Fasanya ${ }^{1}$, Oluwatomisin J. Oyewole ${ }^{2}$, Johnson A. Oliyide ${ }^{2}$ \\ ${ }^{1}$ School of Economics and Finance, University of the Witwatersrand, Johannesburg, South Africa, ${ }^{2}$ Department of Economics, Federal University of \\ Agriculture, Abeokuta, Ogun State, Nigeria \\ Keywords: energy markets, infectious diseases uncertainty, predictability \\ $10.46557 / 001 c .21223$
}

\section{Asian Economics Letters}

Vol. 2, Issue 1, 2021

In this note, we examine the predictability of the energy stock markets using the diseases-based uncertainty index within a nonparametric framework. The nonparametric causality test reveals that energy stocks' predictability driven by pandemic uncertainty is prevalent around the lower and upper quantiles for both the full sample of data and for the COVID-19 sample period.

\section{Introduction}

The objective of this study is to examine the role of disease-based uncertainty in predicting energy stock markets. The motivation for our study is threefold. First, the current COVID-19 pandemic has shown that stock markets and financial markets of many countries are sensitive to the pandemic (see, Bouri et al., 2020). Second, uncertainty that created by pandemics that impact health have significant influence on investors' actions (Baker et al., 2020) and sentiments (HaiYue et al., 2020). Lastly, uncertainty due to the pandemic might restrain the demand for energy which subsequently leads to fall in stock prices and returns (see Sharma \& Sha, 2020; and Sha \& Sharma, 2020).

Several studies have documented that the fluctuations in the stock market during the pandemic can be tracked by the uncertainty resulting from economic and non-economic news. For instance, past studies have noted that disasters (Kowalewski \& Śpiewanowski, 2020) and epidemics (C. D. Chen et al., 2009; M.-H. Chen et al., 2007; Ichev \& Marinč, 2018; Salisu \& Adediran, 2020; Salisu \& Vo, 2020) significantly influence the stock market. To be more specific, Salisu \& Adediran (2020) unveil that uncertainty due to the pandemic tracks well the volatility in energy markets in both in-sample and out-of- sample tests. Furthermore, Salisu \& Vo (2020) document that investors started to sell off their stocks during the early stages of the COVID-19 pandemic due to fear of loss. On the other hand, Liu et al. (2020) show that COVID-19 exerts a positive influence on the crude oil and stock returns.

To the best of our knowledge, there is limited understanding about the influence of uncertainty caused by pandemics on the Asia-Pacific energy stocks. On this note, we extend the literature by determining the role of pandemics in predicting energy stocks for the Asia-Pacific market. We partition our estimation into two by considering the full sample of data and the COVID-19 sample of data. To this end, we utilize the novel nonparametric causality-in-quantiles approach recently developed by Balcilar et al. (2018). This approach is capable of testing non-linear causality of the $k$ th order across all quantiles of the entire distribution of stock returns, and is robust to the presence of misspecification errors, structural breaks and frequent outliers, which are commonly found in financial time series data (Balcilar et al., 2018). Another motivation for using the nonparametric quantile-in-causality approach is that when we conduct a test for nonlinearity by applying the Brock et al. (BDS, 1996), the BDS test validates the adoption of the non-linear causality-in-quantiles approach (see for example Fasanya et al., 2021).

The rest of the paper is structured as follows. Section II provides a description of the methodology. Section III discusses the data and results and Section IV concludes.

\section{Methodology}

This paper follows Balcilar et al. (2018) methodology, which is an extension of Nishiyama et al. (2011) and Jeong et al. (2012) nonlinear causality frameworks. As noted by Jeong et al. (2012), the variable $x_{t}$ (EMV-ID) does not cause $y_{t}$ (energy stock returns) in the $\sigma-$ quantile with respect to the lag-vector of $\left\{y_{t-1}, \ldots, y_{t-q}, x_{t-1}, x_{t-q}\right\}$ if

$$
\begin{array}{r}
Q_{\sigma}\left(y_{t} \mid y_{t-1}, \ldots, y_{t-q}, x_{t-1}, \ldots, x_{t-q}\right) \\
=Q_{\sigma}\left(y_{t} \mid y_{t-1}, \ldots, y_{t-q}\right)
\end{array}
$$

While $x_{t}$ causes $y_{t}$ in the $\sigma$ th quantile with respect to $\left\{y_{t-1}, \ldots, y_{t-q}, x_{t-1}, x_{t-q}\right\}$ if

$$
\begin{array}{r}
Q_{\sigma}\left(y_{t} \mid y_{t-1}, \ldots, y_{t-q}, x_{t-1}, x_{t-q}\right) \\
\neq Q_{\sigma}\left(y_{t} \mid y_{t-1}, \ldots, y_{t-q}\right)
\end{array}
$$

Thus, they adopt the nonparametric Granger-quantilecausality approach of Nishiyama et al. (2011). To illustrate the causality in higher order moment, they assume: 


$$
y_{t}=h\left(V_{t-1}\right)+\vartheta\left(U_{t-1}\right) \tau_{t}
$$

Where $\tau_{t}$ is the white noise process and $h(\cdot)$ and $\vartheta(\cdot)$ equal the unknown functions that satisfy pertinent conditions for stationarity. Although this specification allows non granger-type causality testing from $U_{t-1}$ to $y_{t}$, however, it could detect the "predictive power" from $U_{t-1}$ to $y_{t}^{2}$ when $\vartheta(\cdot)$ is a general nonlinear function. Thus, Equation (3) is re-formulated to account for the null and alternative hypothesis for causality in Equations 4 and 5, respectively.

$$
\begin{aligned}
& H_{0}=P\left\{F_{y_{t}^{2} \mid W_{t-1}}\left\{Q_{\sigma}\left(y_{t} \mid W_{t-1}\right)\right\}=\sigma\right\}=1, \\
& H_{1}=P\left\{F_{y_{t}^{2} \mid W_{t-1}}\left\{Q_{\sigma}\left(y_{t} \mid W_{t-1}\right)\right\}=\sigma\right\}<1,
\end{aligned}
$$

We obtain the feasible test statistic for testing the null hypothesis in Equation (4). With the inclusion of the Jeong et al. (2012) approach, Balcilar et al. (2018) overcome the issue that causality in mean implies causality in variance. Specifically, they interpret the causality in higher-order moments through the use of the following model:

$$
y_{t}=h\left(U_{t-1}, V_{t-1}\right)+\tau_{t},
$$

Thus, the higher order quantile causality is:

$$
\begin{array}{r}
H_{0}=P\left\{F_{y_{t}^{k} \mid W_{t-1}}\left\{Q_{\sigma}\left(y_{t} \mid W_{t-1}\right)\right\}=\sigma\right\}=1, \\
\text { for } k=1,2, \ldots, k, \\
H_{1}=P\left\{F_{y_{t}^{k} \mid W_{t-1}}\left\{Q_{\sigma}\left(y_{t} \mid W_{t-1}\right)\right\}=\sigma\right\}<1, \\
\text { for } k=1,2, \ldots, k .
\end{array}
$$

Overall, we test that $x_{t}$ Granger causes $y_{t}$ in $\sigma$ th quantile up to the $k$-th moment through the use of Equation (7) to construct the test statistic of the equation of the first moment (null hypothesis) for each $k$. Failure to reject the null of $k=1$ does not translate into non-causality in variance, thus, we construct the tests for $k=2$. Finally, we test for the existence of causality-in-mean and variance.

\section{Data and Results \\ A. Data and Preliminary Analyses}

This paper covers energy stock indices (from which stock returns are computed) of 10 Asia-Pacific countries. These countries are Australia, China, Hong Kong, India, Indonesia, Japan, Korea, Singapore, Taiwan, and Thailand. We use daily data from January 1, 2004 to August 31, 2020 based on data availability. The analyses are conducted using both the full sample and the sample covering the COVID-19 pandemic $(01 / 01 / 2020$ to $31 / 08 / 2020)$. Data on the energy stock indices are obtained from the Thomson Reuters DataStream, and the Infectious Disease Equity Market Volatility (EMVID), developed by Baker et al. (2020) and is available for download from http://www.policyuncertainty.com.

Table 1 highlights the relevant descriptive properties of the data. The energy stock indices of all countries consid- ered have positive returns on average, except for China, Japan, and Singapore, which carry negative average returns. However, a large difference is observed between the maximum and minimum values across all series, indicating potential high levels of fluctuations. Based on the standard deviation statistic, the Indonesian stock market is the most volatile while the Australian market experiences the least volatility. Concerning the statistical distribution of the return series, the skewness measure suggests that stock returns of Korea and Singapore are positively skewed, which means they have a long right tail while all others exhibit negative skewness. The kurtosis statistics also reveal that all series are largely leptokurtic (highly peaked). The Jarque-Bera statistic confirms non-normality. Furthermore, we explore the random walk properties of all the variables using the Ng-Perron, and Dickey-Fuller GLS tests, and all series appear to be stationary at the $5 \%$ significance level. This is a pre-requisite for our causality analysis.

\section{B. Results}

We begin the analysis by examining the causal effect of uncertainties due to infectious disease outbreaks on the returns of each of the energy stock indices from a linear perspective. ${ }^{1}$ However, we perceive this may likely be due to nonlinearity in the series, as the presence of heavy tails, excess kurtosis, and non-normality are suggestive of the possibility of the nonlinear nature of the series.

Furthermore, to confirm our suspicion, we conduct a more formal test (BDS test) developed by Broock et al. (1996) to establish the presence of nonlinearity in the series. The BDS test results for the full sample and the COVID-19 regimes are reported in Table 2. Our analysis shows strong evidence of a nonlinear relationship between EMV_ID and all return series as the null hypothesis of serial dependence is rejected at the highest levels of significance for all countries except China, Indonesia, and Taiwan (Panel B). These results imply strong evidence of nonlinearity in the relationship between EMV_ID and energy stock returns. This means that relying on the linear Granger-causality test may lead to spurious conclusions as it could have suffered from misspecification errors.

Having established nonlinearity, we turn to the results of the quantiles-based causality tests. Figures $\underline{1}$ and $\underline{2}$ summarize the results of the nonparametric causality-in-quantiles in conditional mean and conditional variance tests, respectively. Each country's stock-market returns are regressed on the EMV_ID. The horizontal axis shows the quantiles, and the vertical axis shows the test results. The blue horizontal line represents the $90 \%$ critical value. The red line represents the results for the full sample, and the grey line represents the results for the COVID-19 sample. 
Table 1: Preliminary test results

\begin{tabular}{|c|c|c|c|c|c|c|c|c|c|}
\hline \multirow[b]{2}{*}{ Countries } & \multicolumn{7}{|c|}{ Panel A: Summary Statistics } & \multicolumn{2}{|c|}{ Panel B: Unit Root Test } \\
\hline & Mean & Max. & Min. & Std. Dev. & Skewness & Kurtosis & JB Stat. & Ng-Perron & DF-GLS \\
\hline Australia & 0.010 & 9.5502 & -18.4318 & 1.5476 & -0.8564 & 13.1282 & $19115.73^{* * *}$ & $-2168.55^{* * *}$ & $-62.840^{* * *}$ \\
\hline China & -0.0055 & 9.4292 & -21.6925 & 1.8248 & -0.2810 & 13.2020 & $18913.26^{* * *}$ & $-2173.32^{* * *}$ & $-66.532^{* * *}$ \\
\hline Hong Kong & 0.0305 & 19.1451 & -15.476 & 2.1868 & -0.0703 & 9.8115 & $8409.035^{* * *}$ & $-2167.47^{* * *}$ & $-62.539^{* * *}$ \\
\hline India & 0.0288 & 16.4636 & -16.4616 & 1.7069 & -0.7074 & 15.1549 & $27128.23^{* * *}$ & $-20.334^{* *}$ & $-5.005^{* * *}$ \\
\hline Indonesia & 0.0373 & 19.7579 & -31.5353 & 2.3715 & -0.3546 & 15.5845 & $28782.29^{* * *}$ & $-2167.70^{* * *}$ & $-62.600^{* * *}$ \\
\hline Japan & -0.0046 & 12.3267 & -14.0222 & 1.8115 & -0.2558 & 7.3283 & $3441.368^{* * *}$ & $-2171.78^{* * *}$ & $-64.091^{* * *}$ \\
\hline Korea & 0.0214 & 16.9346 & -14.5847 & 2.0804 & 0.0926 & 8.8016 & $6104.06^{* * *}$ & $-153.765^{* * *}$ & $-13.612^{* * *}$ \\
\hline Singapore & -0.0017 & 13.8816 & -12.7891 & 1.7366 & 0.0632 & 10.3514 & $9793.816^{* * *}$ & $-1133.24^{* * *}$ & $-27.644^{* * *}$ \\
\hline Taiwan & 0.0142 & 9.4433 & -11.2462 & 1.5797 & -0.0816 & 7.2166 & $3225.848^{* * *}$ & $-2171.46^{* * *}$ & $-67.971^{* * *}$ \\
\hline Thailand & 0.0121 & 14.078 & -30.0363 & 1.8795 & -1.0876 & 25.4200 & $91921.72^{* * *}$ & $-1981.06^{* * *}$ & $-44.906^{* * *}$ \\
\hline EMV_ID & 1.2457 & 68.37 & 0 & 5.1161 & 7.1915 & 62.9391 & $688354.6^{* * *}$ & $-25.067^{* * *}$ & $-3.553^{* * *}$ \\
\hline
\end{tabular}

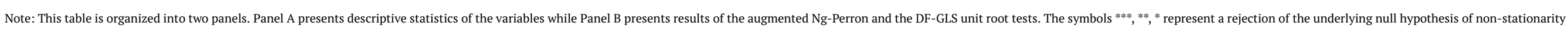
at the $1 \%, 5 \%$, and $10 \%$ levels of significance, respectively. 


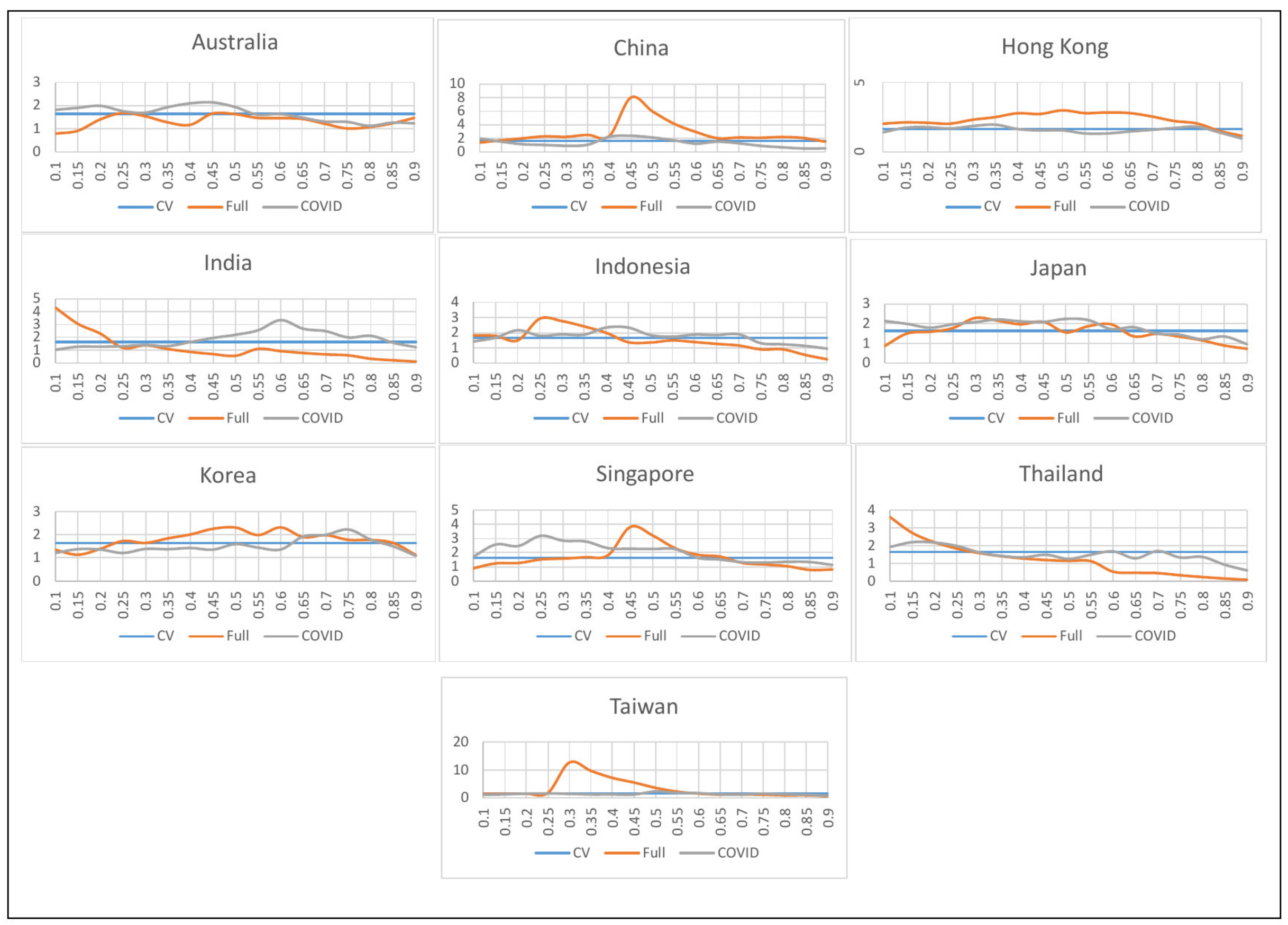

Figure 1: Quantile-based (nonlinear) causality test in conditional mean

Note: The above figures are graphical representations of the causality-in-quantiles in conditional mean and conditional variance results. CV represents critical value at the $10 \%$ level. 


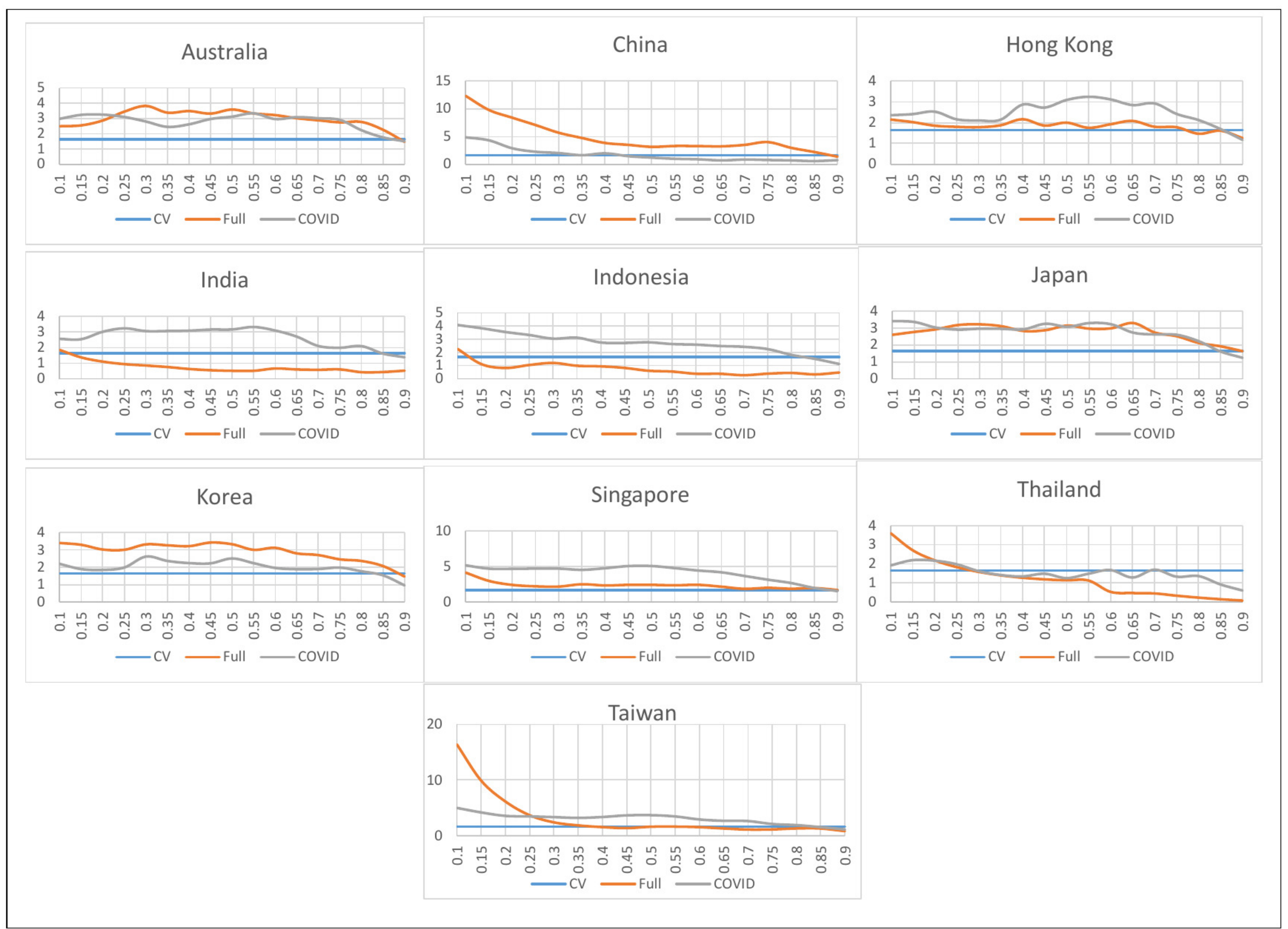

Figure 2: Quantile-based (nonlinear) causality test in conditional variance

Note: The above figures are graphical representations of the causality-in-quantiles in conditional mean and conditional variance results. CV represents critical value at the $10 \%$ level. 
Table 2: BDS Test Results

\begin{tabular}{|c|c|c|c|c|c|}
\hline \multicolumn{6}{|c|}{ Panel A: Full sample } \\
\hline & 2 & 3 & 4 & 5 & 6 \\
\hline Australia & $0.0221^{* * *}$ & $0.0439^{* * *}$ & $0.0600^{* * *}$ & $0.0696^{* * *}$ & $0.0735^{* * *}$ \\
\hline China & $0.0275^{* * *}$ & $0.0567^{* * *}$ & $0.0793^{* * *}$ & $0.0931^{* * *}$ & $0.0994^{* * *}$ \\
\hline Hong Kong & $0.0223^{* * *}$ & $0.0452^{* * *}$ & $0.0631^{* * *}$ & $0.0748^{* * *}$ & $0.0794^{* * *}$ \\
\hline India & $0.0200^{* * *}$ & $0.0406^{* * *}$ & $0.0546^{* * *}$ & $0.0618^{* * *}$ & $0.0642^{* * *}$ \\
\hline Indonesia & $0.0264^{* * *}$ & $0.0504^{* * *}$ & $0.0678^{* * *}$ & $0.0782^{* * *}$ & $0.0823^{* * *}$ \\
\hline Japan & $0.0138^{* * *}$ & $0.0286^{* * *}$ & $0.0394^{* * *}$ & $0.0454^{* * *}$ & $0.0480^{* * *}$ \\
\hline Korea & $0.0154^{* * *}$ & $0.0310^{* * *}$ & $0.0429^{* * *}$ & $0.0504^{* * *}$ & $0.0531^{* * *}$ \\
\hline Singapore & $0.0326^{* * *}$ & $0.0617^{* * *}$ & $0.0844^{* * *}$ & $0.0981^{* * *}$ & $0.1057^{* * *}$ \\
\hline Taiwan & $0.0117^{* * *}$ & $0.0254^{* * *}$ & $0.0347^{* * *}$ & $0.0398^{* * *}$ & $0.0418^{* * *}$ \\
\hline Thailand & $0.0202^{* * *}$ & $0.0419^{* * *}$ & $0.0572^{* * *}$ & $0.0645^{* * *}$ & $0.0670^{* * *}$ \\
\hline \multicolumn{6}{|c|}{ Panel B: During COVID-19 } \\
\hline Australia & $0.0408^{* * *}$ & $0.0828^{* * *}$ & $0.1185^{* * *}$ & $0.1342^{* * *}$ & $0.1347^{* * *}$ \\
\hline China & 0.0111 & 0.0176 & $0.0321^{* *}$ & $0.0370^{* * *}$ & $0.0353^{* * *}$ \\
\hline Hong Kong & $0.0206^{* * *}$ & $0.0476^{* * *}$ & $0.0562^{* * *}$ & $0.0661^{* * *}$ & $0.0687^{* * *}$ \\
\hline India & $0.0168^{* *}$ & $0.0378^{* * *}$ & $0.0515^{* * *}$ & $0.0552^{* * *}$ & $0.0577^{* * *}$ \\
\hline Indonesia & -0.0051 & 0.0138 & $0.0257^{* *}$ & $0.0313^{* * *}$ & $0.0305^{* * *}$ \\
\hline Japan & $0.0186^{* * *}$ & $0.0299^{* * *}$ & $0.0440^{* * *}$ & $0.0468^{* * *}$ & $0.0454^{* * *}$ \\
\hline Korea & $0.0297^{* * *}$ & $0.0600^{* * *}$ & $0.0734^{* * *}$ & $0.0797^{* * *}$ & $0.0772^{* * *}$ \\
\hline Singapore & $0.0275^{* * *}$ & $0.0523^{* * *}$ & $0.0743^{* * *}$ & $0.0906^{* * *}$ & $0.0953^{* * *}$ \\
\hline Taiwan & 0.0008 & 0.0182 & $0.0280^{*}$ & $0.0367^{* *}$ & $0.0347^{* *}$ \\
\hline Thailand & $0.0370^{* * *}$ & $0.0817^{* * *}$ & $0.1131^{* * *}$ & $0.1304^{* * *}$ & $0.1336^{* * *}$ \\
\hline
\end{tabular}

Note: Values in the cell represent the BDS test statistic. The symbols ******** represent the rejection of the underlying null hypothesis of linearity at the $1 \%, 5 \%$, and $10 \%$ levels of significance, respectively.

Our results show strong evidence supporting the rejection of the null hypothesis of no Granger-causality for both the full sample and for the COVID-19 period. The causal evidence is most significant at the lower and upper quantiles with a few reaching the median region. This indicates a strong causal relationship between uncertainty due to infectious diseases and energy stock returns in the Asia-Pacific region. By implication, investors in the Asia- Pacific energy market may need to consider the likely effects of global pandemics in the valuation of risk-adjusted returns for energy stocks in particular and perhaps in their diversification of financial assets in general. The risk management framework should be reassessed to address new and enhanced risks caused by the COVID-19 pandemic.

\section{Conclusion}

In this study, we examine the causal relationship be- tween uncertainties due to infectious disease outbreaks and the Asia-Pacific energy market. We utilize a new dataset by Baker et al. (2020) and employ the nonparametric quantilebased approach. Our findings strongly support the nonlinear causal relationship between uncertainties due to infectious disease outbreaks and the Asia-Pacific energy market. Investors may need to consider the likely effects of global pandemics in the valuation of risk-adjusted returns for energy stocks in particular and perhaps in their diversification of financial assets in general. This conclusion complements the emerging literature on the vulnerability of the energy market to the COVID-19 pandemic.

Submitted: January 31, 2021 AEDT, Accepted: February 22, 2021 AEDT 


\section{REFERENCES}

Baker, S. R., Bloom, N., Davis, S. J., \& Terry, S. (2020). Covid-induced economic uncertainty (NBER Working Paper No. 26983). National Bureau of Economic Research. https://doi.org/10.3386/w26983

Balcilar, M., Gupta, R., Pierdzioch, C., \& Wohar, M. E. (2018). Terror attacks and stock-market fluctuations: Evidence based on a nonparametric causality-inquantiles test for the G7 countries. The European Journal of Finance, 24(4), 333-346. https://doi.org/1 0.1080/1351847x.2016.1239586

Bouri, E., Cepni, O., Gabauer, D., \& Gupta, R. (2020). Return Connectedness across Asset Classes around the COVID-19 Outbreak. University of Pretoria,

Department of Economics Working Paper Series. http s://doi.org/10.1016/i.irfa.2020.101646

Broock, W. A., Scheinkman, J. A., Dechert, W. D., \& LeBaron, B. (1996). A test for independence based on the correlation dimension. Econometric Reviews, 15(3), 197-235. https://doi.org/10.1080/0747493960880035 $\underline{3}$

Chen, C. D., Chen, C. C., Tang, W. W., \& Huang, B. Y. (2009). The positive and negative impacts of the SARS outbreak: A case of the Taiwan industries. J. Dev. Areas, 43, 281-293.

Chen, M.-H., Jang, S. S., \& Kim, W. G. (2007). The impact of the SARS outbreak on Taiwanese hotel stock performance: An event-study approach. International Journal of Hospitality Management, 26(1), 200-212. https://doi.org/10.1016/j.ijhm.2005.11.004

Fasanya, I., Oyewole, O., \& Odei-Mensah, J. (2021). Infectious diseases-energy futures nexus: A quantileon-quantile approach. Energy Research Letters, 1(4). $\underline{\mathrm{h}}$ ttps://doi.org/10.46557/001c.18267

HaiYue, L., Yile, W., Dongmei, H., \& Cangyu, W. (2020). Short term response of Chinese stock markets to the outbreak of COVID-19. Applied Economics. http s://doi.org/10.1080/00036846.2020.1776837

Ichev, R., \& Marinč, M. (2018). Stock prices and geographic proximity of information: Evidence from the Ebola outbreak. International Review of Financial Analysis, 56, 153-166. https://doi.org/10.1016/i.irfa.2 $\underline{017.12 .004}$
Jeong, K., Härdle, W. K., \& Song, S. (2012). A Consistent Non-parametric Test for Causality in Quantile. Econometric Theory, 28(4), 861-887. http s://doi.org/10.1017/s0266466611000685

Kowalewski, O., \& Śpiewanowski, P. (2020). Stock market response to potash mine disasters. Journal of Commodity Markets, 20, 100124. https://doi.org/10.10 16/j.jcomm.2020.100124

Liu, L., Wang, E.-Z., \& Lee, C.-C. (2020). Impact of the COVID-19 pandemic on the crude oil and stock markets in the US: A time-varying analysis. Energy Research Letters, 1(1). https://doi.org/10.46557/001c.1 $\underline{3154}$

Nishiyama, Y., Hitomi, K., Kawasaki, Y., \& Jeong, K. (2011). A consistent non-parametric test for nonlinear causality-specification in time series regression. Journal of Econometrics, 165(1), 112-127. $\underline{\mathrm{h}}$ ttps://doi.org/10.1016/i.jeconom.2011.05.010

Salisu, A. A., \& Adediran, I. (2020). Uncertainty due to infectious diseases and energy market volatility. Energy Research Letters, 1(2). https://doi.org/10.4655 7/001c.14185

Salisu, A. A., \& Vo, X. V. (2020). Predicting stock returns in the presence of COVID-19 pandemic: The role of health news. International Review of Financial Analysis, 71, 101546. https://doi.org/10.1016/i.irfa.20 $\underline{20.101546}$

Sha, Y., \& Sharma, S. S. (2020). Research on Pandemics Special Issue of the Journal Emerging Markets Finance and Trade. Emerging Markets Finance and Trade, 56(10), 2133-2137. https://doi.org/10.108 0/1540496x.2020.1795467

Sharma, S. S., \& Sha, Y. (2020). Part A: Special Section on COVID-19 Research. Emerging Markets Finance and Trade, 56(15), 3551-3553. https://doi.or $\mathrm{g} / 10.1080 / 1540496 x .2020 .1858617$ 